\title{
Using Reciprocal Teaching Strategy to Improve Physics Students' Critical Thinking Ability
}

\author{
Nofouz Mafarja $^{1}$ (D), Hutkemri Zulnaidi ${ }^{1^{*}}$ (D), Hidayah Mohd. Fadzil ${ }^{1}$ \\ ${ }^{1}$ Department of Mathematics and Science Education, Faculty of Education, University of Malaya, Kuala Lumpur, MALAYSIA
}

Received 2 October 2021 - Accepted 21 December 2021

\begin{abstract}
In Palestine, issues about word problem solving and physics critical thinking have led to a deep understanding of factors affecting physics problem solving among Palestinian students. The influence of Reciprocal Teaching on physics students' critical thinking skills among 10th-grade students in Palestine was investigated in the study. The study used a quasi-experimental research design. Two treatment groups (male and female) and two control groups were randomly allocated to four intact courses (male and female). All four groups included a total of 120 participants who were pre- and post-tested on their critical thinking skills in physics. Preliminary checks were performed prior to inferential testing to ensure that the one-way MANCOVA assumptions were not violated. After adjusting for physics word problem-solving pre-test scores for critical thinking skills, one-way MANCOVA results show that reciprocal teaching strategy has a considerable effect on critical thinking skills at $p<.05$ level between the groups $F(1,118)=336.649$, $p=.001<.05$. In addition, the two-way MANCOVA results for the interaction effect of gender and method is not large in critical thinking skills, with $F(1,116)=3.5, p=.064>.05$ but is big in two sub-skills interpretation, with $F(1,116)=5.187, p=.025<.05$, and evaluating arguments skill, with $F(1$, $116)=5.463, p=.021<.05$ in favour for male students. As a result, using a reciprocal teaching technique to learn physics topics is more effective than using a standard method, and it is applicable and effective for both male and female students. This study has implications for policymakers to encourage the implementation of an integrated reciprocal teaching strategy in schools. It also has implications for teachers' instructional practices in the classroom.
\end{abstract}

Keywords: reciprocal teaching, traditional method, critical thinking ability, reading comprehension, metacognitive

\section{INTRODUCTION}

Science is defined as the systematic study or knowledge acquired through observation or practice. Physics is one of the frequent research areas that shape applicable models of reality (Agnes, 2013). As teachers face challenges from students seeking to gain experience and professional achievements, they encounter difficulties in using different strategies, applying technical options, and intervening to address learning gaps, such as deficiencies in an announcement's comprehension and understanding (Star, 2013). This could surpass a scientific subject to address word problems, as the idea needs focus and engagement to be understood. To solve numerical problems, comprehension and understanding are necessary. Koch and Eckstein (2005) proposed that verbal physics problems could be solved through high-level skills, which are viewed in the form of long sentences. Math problems and reading comprehension results were closely correlated with each other. Similar to this strategy is followed in numerical physics, where the reciprocal teaching strategy enhances reading comprehension. The reciprocal teaching strategy is a teaching method that supports the teacher.

Reciprocal teaching is an interactive strategy developed to improve students' comprehension and develop meta-knowledge behaviours, which are defined as thinking about and perceiving what they know and what they do not know, including organisational

(c) 2022 by the authors; licensee Modestum. This article is an open access article distributed under the terms and conditions of the Creative Commons Attribution License (http://creativecommons.org/licenses/by/4.0/). 


\section{Contribution to the literature}

- Reciprocal teaching assists students to understand physics concepts exceptionally well in comparison to the traditional method. Also, it can improve critical thinking skills in physics more than traditional methods.

- Reciprocal teaching improved interpretation and evaluating argument skills for male students more than female students, whereas the traditional method did not improve interpretation and evaluating arguments skills for male and female students.

- Inference, recognizing assumption, and deduction skills between male and female learning did not vary via reciprocal teaching.

procedures to manage processes. With its four functions (i.e. predictor, clarifier, questioner, and summarise) (Oczkus, 2013), reciprocal teaching acts like a scaffolding strategy to spice up learning challenges. RT was first used by Palincsar and Brown (1984) to cope with distractions. It produces an engaging atmosphere that includes each student by allocating a selected mandatory function to minimise several effects of insufficient concern and create a vibrant atmosphere. They found that RT works like 'reading vitamins'. Evidence shows that students have been positively enriched by using the four functions in ways different from the knowledge of reading quality. Students were found wholly committed and enthusiastic about the strategies offered.

Yvonne et al. (2009) viewed that RT increases students' trust, and its style convinces them to learn to improve understanding and learning accomplishment. This approach offers strategic learning as students know their weak areas and are aware of their reading deficiencies. In the same vein, Phillipa (2010) argued that students could read texts but do not have the competence to do what it means. Teachers should exercise RT productively as a teaching technique to improve comprehension and critical thinking (for word problems). Critical thinking is a comprehensible and accessible review that determines what to be concerned with or what to do (Ennis, 2011). By this definition, critical thinking emphasises thinking that is reasonable and reflective. Critical thinking is about solving problems with critical qualities and abilities: curiosity, risk-taking and always respecting the rights of others and training high-level thinking (Aljaafreh, 2013; Larsson, 2017). High-level thinking is achieved through inner level thinking activities. To think that the required level (lower-order thinking) is utilising only a limited capacity for ordinary and mechanical things.

High-order thinking allows students to justify, analyse or possibly manipulate the above information not to become monotonous. Critical thinking is about finding, acquiring, evaluating, analysing, balancing and imagining information as an instructor to developing the thinking with self-awareness, therefore involving creativity and risk-taking-the ability to use data (Yildirim \& Ozkerman, 2011). Teachers are expected to plan education so that students become interested in finding out if they can think critically during the learning process. Teachers are the factors that determine most educational programmes' success, especially in primary education. The first establishment with a potential student event should be responsible for understanding students' generation throughout life (Noone \& Hogan, 2016; Renjith Kumar \& James, 2015; Song, 2016; Tiruneh et al., 2018). Students are not highly capable of identifying arguments. Moreover, students do not have direct experiences in an authentic and basic understanding of the abstract; hence, they cannot understand which logic is wrong. Students involved in group discussions have little knowledge of what information, opinions and assumptions are. Students' critical thinking skills may not be well-developed due to schools that do not strengthen learners' critical thinking skills.

The government is at the top of educational reform. The teaching and learning of physics receive much attention (science education). A tactic is considered in RT, but this approach is still not correctly practised in Palestine. Physics is the primary science topic that requires a high-level ability to explain concepts, especially numerical concepts that concentrate on the eight stages of RT, namely, predicting, generating questions, clarifying, connecting, calculating, visualising, summarising and giving feedback. Using a defined research design can boost students' cognitive development and metacognitive development at the secondary level. Meyer (2014) believed that the interactive process of learning facilitates group effort, and places or develops links to the meaning of a text. Figure 1 shows the instructional process for reciprocal teaching.

\section{LITERATURE REVIEW}

Vygotsky (1978) stated that the development of knowledge by social interaction is the foundation for reciprocal teaching. Furthermore, Vygotsky (1978) suggested clarifying confusing concepts and reorganising and arranging learning and thinking for cognitive development, for example, discussing aloud facilitates easy understanding of concepts and sharing of knowledge. Its proximal development area is crucial for defining appropriate content and device operations for 


\begin{tabular}{|c|c|}
\hline Predicting & $\begin{array}{l}\text { - Developing hypotheses, building new knowledge and } \\
\text { anticipating results }\end{array}$ \\
\hline Generating questions & - substance for self test \\
\hline Clarifying & $\begin{array}{l}\text { - Unclear reference words } \\
\text { - Vocabulary and difficult concepts }\end{array}$ \\
\hline Connecting & $\begin{array}{l}\text { - Connecting the problem with past knowledge } \\
\text { - How have you solved similar problems in the past? }\end{array}$ \\
\hline Calculating & $\begin{array}{l}\text {-Solving the problem and show all their working out and } \\
\text { thinking }\end{array}$ \\
\hline Visualising & $\begin{array}{l}\text {-Draw diagrams, pictures, tables, or other representations } \\
\text { to help you solve the problem }\end{array}$ \\
\hline Summarising & $\begin{array}{l}\text {-Identifying paraphrases, summarizing and integrated } \\
\text { information }\end{array}$ \\
\hline Giving feedback & $\begin{array}{l}\text { - Teacher giving constructive comments to all students } \\
\text { about their participation }\end{array}$ \\
\hline
\end{tabular}

Figure 1. Instructional process for reciprocal teaching

enhanced learning and performance (Galloway, 2009). These contents must be shared at an entirely different level, which must be acceptable to the level of learning ability and understanding of students. A framework for promoting and realising feedback for ending reciprocal teaching practices must be accessible (Oczkus, 2003).

However, Favell (1976) and Brown (1978) considered the first study of metacognition. They work provided an understanding of a learner's reflection process and insight into how a reader's perception affected selfregulation in various aspects of reading. A shared understanding of metacognitive methods has emerged despite the different theoretical elements from the early framework conditions. Metacognition consists of two components: cognitive understanding and, as a result, cognitive control. Metacognitive information is referred to as learner cognitive knowledge; Favell (1976) calls self-awareness of aspects of a task and understanding its use. Self-regulation is related to normal behaviour and, therefore, to the learning objectives of a reader. Metacognitive monitoring is the process of assessing or assessing the current or continuous state of cognitive activity, whereas metacognitive control refers to ongoing cognitive training (Stephanou \& Mpiontini, 2017). Metacognition's self-regulatory component includes cognitive activities such as planning, testing, evaluation, and testing and modifying techniques. Presley et al. (1985) argued that rational knowledge is 'potentially aware and controllable'.

\section{Reciprocal Teaching}

$\mathrm{RT}$ is an effective technique that is used not only in understanding English reading; it is widely used in most subjects. It is designed as an instructional technique, which allows students to develop their reading comprehension in all subject matters (Blazer, 2007). Reciprocal teaching decreases students' position because they are fulfilled when they share their feelings, viewpoints in an interactive session and share their opinions through learning approaches. Learning areas include opportunities to strengthen awareness, recognise and observe misconceptions, and amend them through this process. Reciprocal teaching has become a learning community whose participants share interaction-related roles that include learning interactions (Ahiri et al., 2018; Navaie, 2018).

Alemu (2020) explored reciprocal peer tutoring in conjunction with direct teaching approaches to increase students' success in content-focused and high-stakes examination-oriented secondary school physics instruction. Data were obtained from three comparable grade-9 sections and assigned to a few distinct intervention groups in a pre-test post-test multi-level quasi-experimental design. The findings revealed that reciprocal peer tutoring as a unified classroom pedagogy aided all students in improving their physics achievement to some extent while not negatively impacting their learning process. These effects are more prominent for those who were in an inferior position and female high school students. If the recurrent failure of blending pedagogy remains, then another replication study using a comparison cluster was advised to find clear proof. Supporting Alemu (2020), Oludipe (2014) confirmed that RT better comprehends English and science subjects where the construct could be fused to show various science concepts. 


\section{Critical Thinking}

Ahiri et al. (2018) examined the impact of differentiation in peer learning and group research models on students' critical thinking skills. The participants in this study were 11th-grade students from Kendari's High School 6. The essay-type test is intended to assess a student's ability to think critically (reasonable confidence level 0.874). Information normality is assessed by using the Shapiro-Wilk test, whereas data homogeneity is assessed by using the Leuven test. To test research hypotheses, the student t-test is utilised. The findings reveal a big change in students' critical thinking abilities before and after the implementation of the peer learning approach. Before and after using the group research approach, major variations were observed in students' critical thinking abilities. Scientists who are taught in a peer-learning paradigm have higher critical thinking abilities than those who are trained in a group research approach. Therefore, if we want to enhance students' critical thinking, particularly in economics, then peer-learning is a good approach.

Olimat et al. (2018) used a quasi-experimental approach founded on two groups' design, pre- and postexperimental. The study sample consisted of 80 students, and randomised recruitments were used to divide them into two equal groups. The control model and critical thinking skills were tested on the study model by utilising practical and traditional methods taught using mutual teaching techniques. Following the statistical method, the research results showed that the cumulative and experimental groups (interpretation, argument evaluation, induction, and reduction) were in favour of the experimental group's critical thinking skill level and the post-test control. The average scores were considerable (but not the experimental group average, and no considerable statistical distinction was observed between the mean scores of the experimental group and those of the control group in the post-test in the assumptions knowledge skill. Finally, we presented a set of recommendations related to the results of this experience.

Araujo and Carneiro (2016) recognised that reciprocal teaching is exceptionally productive for deciphering biology texts by reading Associate in Nursing. Besides, RT in biology has allowed a detailed study of complex text and an understanding of the means of scientific terminology. Typically, the interpretation of a text in biology reveals two or more meanings that require abstract explanation. However, with the RT method, many academically challenged students improved. Compared with those subjected to the same old methods, the understanding of students taught with RT shifted. In the field of biology, intervention students felt extra optimistic and results-oriented. The syntax of reciprocal teaching strategy can train critical thinking skills because it can improve students' ability and desire to read. This fact is corroborated by Sundahry et al. (2018); they found that reciprocal teaching is an instructional method in which small groups of students learn to comprehend through scaffolds. Meyer (2014) believed that the interactive learning process promotes a group's effort and position or establishes connections with the means of the text. In this study, the researchers used eight steps to apply reciprocal teaching strategies: predicting, clarifying, questioning, visualising, connecting, calculating, summarising, and giving feedback.

\section{Traditional Method}

Teacher-centred activities involve traditional methods of education such as dictation, drilling and explaining (Alsaraireh \& Hamid, 2016). The traditional method is typically the teacher-led conference method in many unindustrialised countries, including Palestine. It is the method of transmitting the truth. Alsaraireh and Hamid (2016) notes that it is older, simpler and more discourse-oriented than modern methods, and that the upper class is a suitable third-party strategy. Although broadly criticised via means of advanced revolutionary academics, its relevance exists in shape and content. Instructors' effectiveness in using the lecture technique lies in rich content, breaks, a tone change and effective presentation. Its inherent obstacles may be mitigated via different interventions, including reciprocal teaching and additional innovations. This study explored the strengths and weaknesses of two teaching methodsmutual education and traditional teaching (Hyun et al., 2017). According to Guise et al. (2017), tertiary-based techniques are ideal for major courses. Although such techniques are heavily condemned by progressive educators, it is suitable in both form and substance. Rich information, pauses in delivery, a change of voice, exemplification and a forceful mode of presentation are factors that contribute to a teacher's efficiency when employing the lecture technique.

\section{METHODOLOGY}

\section{Research Design}

Pre- and post-testing four groups were involved in the study, two of which were experimental (male and female), and the other two were control groups (male and female) (Maciejewski, 2018). The two experimental groups were taught by using the new treatment, which is RT, whereas the control groups were taught by utilising the traditional methods. Each of the four groups had 30 participants. Additionally, two teachers were selected to teach the experimental and control groups. The teachers were trained to use RT and were given a specific training manual developed for this purpose. 
Table 1. Sample distribution for the experimental and control group

\begin{tabular}{|c|c|c|c|c|}
\hline Group & Intervention & Gender & Number of students & Total \\
\hline \multirow[t]{2}{*}{ Experimental } & Reciprocal teaching & Male & 30 & 60 \\
\hline & & Female & 30 & \\
\hline \multirow[t]{2}{*}{ Control } & Traditional method & Male & 30 & 60 \\
\hline & & Female & 30 & \\
\hline
\end{tabular}

Table 2. Distribution of sub-skills in critical thinking

\begin{tabular}{|c|c|c|}
\hline Skills & Items & Description \\
\hline Inference & 20 & $\begin{array}{l}\text { The student's ability to determine if the proposed inference is correct, likely accurate, false, likely } \\
\text { false, or inadequate to conclude }\end{array}$ \\
\hline $\begin{array}{l}\text { Recognising } \\
\text { assumption }\end{array}$ & 12 & $\begin{array}{l}\text { The ability of the student to assess and accept the proposed conclusions on the basis of the } \\
\text { statement given }\end{array}$ \\
\hline Deduction & 22 & The ability of the student to make deductions and assumptions for a given argument \\
\hline Interpretation & 14 & $\begin{array}{l}\text { The student's capacity to determine whether or not each of the offered assumptions is logically } \\
\text { founded on the facts given }\end{array}$ \\
\hline $\begin{array}{l}\text { Evaluating } \\
\text { arguments }\end{array}$ & 15 & $\begin{array}{l}\text { The ability of the student to differentiate between weak and substantial reasons for each } \\
\text { statement given }\end{array}$ \\
\hline
\end{tabular}

Table 3. Example of modifications made for items from the original critical thinking test by Watson and Glaser (2010)

\section{Original questions \\ Sub-skill 3: Deduction}

A stone drops from the top of a building to the ground due to gravitational forces, but the Earth's gravity towards things decreases as we travel away from the Earth towards space.

1. When travelling away from Earth at large distances, the gravity of the Earth is absent.

2. Attraction in space influences the attraction of the body to the c. Newton's second law of motion planet.

3. Before a tiny mass, a great mass will hit the Earth.

\section{Sample}

A total of 120 students from 10th grades were involved in this study. Two intact classes are the experimental groups and have 30 female and 30 male students. Another two classes are the control groups and have 30 female and 30 male students. The equality of the fourth group is investigating utilising pre-tests (critical thinking test). The experimental groups are taught by using reciprocal teaching, whereas the control groups are taught by using the traditional method. Table 1 shows the distribution of the participants.

\section{Instruments}

Given that one of the goals of the current study was to use reciprocal education to enhance critical thinking among chosen Palestinian physics secondary students, a critical thinking test was required. After the researcher reviewed different assessments and tests to estimate rational thought (Monica, 2005; Piaw, 2010; Rabari et al., 2011; Tiruneh, 2017; Watson \& Glaser, 1980, 2008, 2010), the essential basis for choosing these tests was the fact that all activities in these tests were correlated with the phenomena of science and physics.

Finally, the researchers prepared the critical thinking test with a total of 83 items about force and motion. From
Modified questions

A sledge sliding on a flat, icy surface with a constant velocity is best described by

a. Newton's first law of motion for objects at rest

b. Newton's first law of motion for objects in motion

d. Newton's third law of motion

the different experiments, the products were adapted and changed the topic to suit the context of the study. The critical thinking test was developed by referring to the concepts in the critical thinking test by Watson and Glaser $(1980,2010)$. As shown in Table 2, Watson and Glaser's $(1980,2010)$ test consists of five abilities to assess critical thinking abilities.

As shown in Table 3, some questions from the actual tests (Monica, 2005; Pressley et al., 1985; Tiruneh, 2017; Watson \& Glaser, 1980, 2010) have been updated, adapted and changed. To help the students understand what is needed, the researcher provided one example to respond to each problem.

The researcher used the same scoring system as in the original test of Watson and Glaser (1980), which is 1 point for a correct answer and 0 for a wrong answer, or if the student had found more than one alternative. The critical thinking test score ranged from 0 to 83 .

\section{Data Analysis}

The findings have been displayed in tabulated form. In Palestine, male and female students go to separate schools; hence, the data from two schools were evaluated. To evaluate critical thinking tests, t-test, mean, SD, normality, homogeneity, one-way 
Table 4. Skewness and kurtosis tests for normality distribution for critical thinking subskills

\begin{tabular}{lcccc}
\hline Sub skills & Mean & SD & Skewness & Kurtosis \\
\hline Inference & 5.35 & 3.36 & 1.58 & 2.00 \\
Recognising assumption & 4.50 & 2.35 & 1.60 & 3.60 \\
Deduction & 5.04 & 2.51 & 1.01 & 2.54 \\
Interpretation & 3.96 & 1.22 & -0.57 & 1.82 \\
Evaluating arguments & 3.88 & 1.40 & -0.72 & 0.54 \\
Overall & 22.71 & 8.86 & 0.58 & 0.70 \\
\hline
\end{tabular}

Table 5. Skewness and kurtosis tests for normality distribution for critical thinking subskills

\begin{tabular}{lcccc}
\hline Critical thinking skills & Levene statistic & df1 & df2 & Sig \\
\hline Inference & .16 & 1 & 118 & 0.680 \\
Recognising assumption & .47 & 1 & 118 & 0.490 \\
Deduction & .003 & 1 & 118 & 0.950 \\
Interpretation & .06 & 1 & 118 & 0.810 \\
Evaluating arguments & 4.93 & 1 & 118 & 0.030 \\
Overall & .60 & 1 & 118 & 0.440 \\
\hline
\end{tabular}

multivariate analysis of covariance (MANCOVA), and two-way MANCOVA were used. To use one-way MANCOVA, one-way MANOVA with a covariate or a one-way ANCOVA is used. Given that this covariate has a linear connection with the dependent variables, adding it to the analysis will help identify discrepancies across groups of independent variables. One-way and two-way MANCOVAs are used to examine any statistically large variation between adjusted averages of three or more independent (unrelated) groups after adjusting for a continuous covariate (Pituch \& Stevens, 2016).

\section{RESULTS}

\section{Difference of Critical Thinking Skills According to Groups}

The assumption of normality must be converged in most parametric tests. The term 'normality' refers to the test's distribution being average (or bell-shaped) with 0 averages, one standard deviation, and symmetric bellshaped curve. Skewness and kurtosis tests were employed to evaluate normality assumption to a presumption of a normal distribution in this study; skewness should be within the range of 2 . Kurtosis readings should be within a 7-point range (George \& Mallery, 2010, 2016). Table 4 shows the normality test for critical thinking subskills.

Table 4 indicates that in both tests (skewness and kurtosis tests), the skewness and kurtosis values are shown along with each component's average and standard deviation. Given that skewness should be within the range of 2, all groups were determined to be normally distributed. Kurtosis values should be within the range of 7 (George \& Mallery, 2010, 2016), which demonstrates the normal distribution in the critical thinking exam for both groups (George \& Mallery, 2010, 2016). The researchers used Levene's test to see if the groups had identical variances on the basis of the premise of homogeneity of variance. This test does not need to be large to satisfy the equality of variances presumption. Table 5 shows the homogeneity of variances in critical thinking abilities.

Table 5 shows that the p-value was $F(1,118)=0.60$, sig $=0.440 \quad(p>0.05)$, demonstrating that in the logical thinking test, no large average variations were observed between the experimental and control groups. However, the findings on the sub-skill of inference $F(1,118)=0.170$, sig $=0.680(p>0.05)$ indicate the absence of considerable distinction in inference between the experimental group and the control groups. Recognising assumption was $\mathrm{F}(1,118)=0.470, \quad$ sig $=0.490 \quad(\mathrm{p}>0.05), \quad$ indicating no considerable distinction among control and experimental groups concerning the recognition of assumption skills. Results obtained for deduction $\mathrm{F}(1,118)=0.003$, sig $=0.950(\mathrm{p}>0.05)$ demonstrate that the variation between the experimental and control groups is not statistically large. Furthermore, the findings on interpretation $(F(1,118)=0.060$, sig $=0.810(p>0.05))$ do not show a large variation in interpretation competence between the control and experimental groups. However, the findings on argument assessment, $F(1,118)=4.940$, sig $=0.030$ affirmative 0.05 , show large variations in argument competence between the control and experimental groups. Consequently, no big differences were observed between the control and experimental groups in the overall level of the five sub-skills for the critical thinking exam: inference, recognising assumption, deduction and interpretation. However, a large difference was observed between the control and experimental groups in judging arguments. Before the intervention, the critical thinking test results of the two groups were almost identical. As a result, the scores of the two groups are nearly identical.

This study aims to see how the reciprocal teaching methodology compares to the traditional method for enhancing critical thinking skills in Palestinian 10thgrade students. The critical thinking exam was given to all of the research samples once the intervention was 
Table 6. Comparison of average value results for critical thinking

\begin{tabular}{|c|c|c|c|c|c|}
\hline \multirow{2}{*}{ Dependent variable } & \multirow{2}{*}{ Group } & \multirow{2}{*}{ Average } & \multirow{2}{*}{ Std. Error } & \multicolumn{2}{|c|}{ 95\% Confidence interval } \\
\hline & & & & Lower bound & Upper bound \\
\hline \multirow[t]{2}{*}{ Inference } & Control group & 7.55 & .43 & 6.7 & 8.41 \\
\hline & Experimental group & 13.77 & .43 & 12.91 & 14.62 \\
\hline \multirow[t]{2}{*}{ Recognition assumption } & Control group & 5.45 & .32 & 4.81 & 6.09 \\
\hline & Experimental group & 8.8 & .32 & 8.16 & 9.44 \\
\hline \multirow[t]{2}{*}{ Deduction } & Control group & 6.28 & .42 & 5.46 & 7.11 \\
\hline & Experimental group & 16.02 & .42 & 15.19 & 16.84 \\
\hline \multirow[t]{2}{*}{ Interpretation } & Control group & 4.25 & .32 & 3.62 & 4.88 \\
\hline & Experimental group & 8.32 & .32 & 7.69 & 8.94 \\
\hline \multirow[t]{2}{*}{ Evaluating arguments } & Control group & 4.92 & .29 & 4.35 & 5.48 \\
\hline & Experimental group & 8.12 & .29 & 7.55 & 8.68 \\
\hline \multirow[t]{2}{*}{ Overall } & Control group & 27.92 & 1.03 & 25.87 & 29.96 \\
\hline & Experimental group & 54.7 & 1.03 & 52.66 & 56.74 \\
\hline
\end{tabular}

completed. The average, standard deviation, and considerable value of the one-way-MANCOVA in the five sub-skills of the critical thinking exam were used to resolve the collected data (inference, assumption recognition, deduction, perception and evaluating arguments). Table 6 compares the critical thinking test results of students in the experimental group who were taught physics by using the reciprocal teaching approach with that of students who were taught physics by using the traditional method.

Table 6 shows the average, value and comparison between the experimental and control groups in the critical thinking subskills. The results demonstrate that all critical thinking abilities increased from pre-test to post-test, showing that the students benefited from the exercise. The result of inference subskill, the reciprocal teaching group and the post-test average was 13.77. In the traditional group, the post-test average was 7.55. Thus, the average variation between the reciprocal teaching and conventional method groups favours the reciprocal teaching group, showing that reciprocal teaching improves the reciprocal teaching group's inference subskills of critical thinking skills more than the traditional method. The result of the reciprocal teaching group in recognising assumption subskill in the post-test average was 8.8 , whereas that of the traditional group was 5.45. Thus, the average variation between the reciprocal teaching and conventional method groups favours the reciprocal teaching group, showing that reciprocal teaching enhances the reciprocal teaching group is recognising assumptions. The reciprocal teaching group's post-test average in deduction skill was 16.02, whereas that of the traditional group was 6.28. Thus, the average variations between the reciprocal teaching and traditional method groups favours the reciprocal teaching group and indicating that the reciprocal teaching improves the deduction subskills of the reciprocal teaching's critical thinking abilities group than the traditional method. In the interpretation subskill, the post-test average of the reciprocal teaching group was 8.32, whereas that of the traditional group was 4.25 .
Thus, the average variation between the reciprocal teaching and traditional method groups favours the reciprocal teaching group and indicates that reciprocal teaching improves the interpretation subskills of the reciprocal teaching group's critical thinking skills more than the traditional method. In evaluating arguments subskill, the post-test average of the reciprocal teaching group was 8.12, whereas that of the traditional group was 4.92. Thus, the average variation between the reciprocal teaching and traditional method groups favours the reciprocal teaching group and indicates that reciprocal teaching improves evaluating arguments subskill of the reciprocal teaching group's critical thinking skills more than the traditional method. In overall critical thinking skills, the post-test average of the reciprocal teaching group was 54.7, whereas that of the traditional group was 27.92 . Thus, the average variation between the reciprocal teaching and traditional method groups favours reciprocal teaching. It indicates that reciprocal teaching enhances the group's overall critical thinking abilities more than the standard technique. The groups' average scores were compared to see whether a large variation exists between them and if reciprocal instruction influenced critical thinking abilities. Oneway MANCOVA was applied to analyse the critical thinking skills. Wilks' lambda was used to interpret the MANCOVA results, because it is robust in accommodating slight violations of assumptions. The result presents that a statistically considerable distinction among the control and experimental groups in critical thinking skills (Wilks' lambda=0.748, $\mathrm{F}(6,113)=55.94$, sig=0.001 $(\mathrm{p}<0.05)$, partial $\mathrm{\eta} 2=0.75)$. This result points to a substantial distinction between reciprocal teaching (experimental group) and regular teaching (control group). The partial multivariate $\mathrm{\eta} 2$ (.75) shows that about $75 \%$ of total variances in critical thinking skills can be attributed to the independent variables (instructional approaches such as reciprocal teaching). Considering that the results were large, we must examine the between-subject effects or the univariate test for each dependent variable, as shown in Table 7. 
Table 7. Test of between-subject effect for critical thinking skills

\begin{tabular}{llccccc}
\hline Source & Dependent variable & DF & Mean square & F & Sig & ${\text { Partial } \eta^{2}}^{2}$ \\
\hline Group & Inference & 1 & 1159.41 & 103.68 & 0.001 & 0.470 \\
& Recognising assumption & 1 & 336.68 & 53.51 & 0.001 & 0.312 \\
& Deduction & 1 & 2842.13 & 271.52 & 0.001 & 0.697 \\
& Interpretation & 1 & 496.13 & 82.66 & 0.001 & 0.412 \\
& Evaluating arguments & 1 & 307.20 & 62.63 & 0.001 & 0.347 \\
& Overall & 1 & 21520.41 & 336.65 & 0.001 & 0.740 \\
\hline
\end{tabular}

Table 8. Comparison of average value results for gender and method in the critical thinking test

\begin{tabular}{|c|c|c|c|c|c|c|}
\hline \multirow{2}{*}{$\begin{array}{l}\text { Dependent } \\
\text { variable }\end{array}$} & \multirow{2}{*}{ Gender } & \multirow{2}{*}{ Method } & \multirow{2}{*}{ Average } & \multirow{2}{*}{ Std. Error } & \multicolumn{2}{|c|}{ 95\% Confidence interval } \\
\hline & & & & & Lower bound & Upper bound \\
\hline \multirow[t]{4}{*}{ Inference } & \multirow[t]{2}{*}{ Male } & Traditional method & 7.40 & 0.61 & 6.18 & 8.62 \\
\hline & & Reciprocal teaching & 14.07 & 0.61 & 12.85 & 15.28 \\
\hline & \multirow[t]{2}{*}{ Female } & Traditional method & 7.70 & 0.61 & 6.48 & 8.92 \\
\hline & & Reciprocal teaching & 13.47 & 0.61 & 12.25 & 14.68 \\
\hline \multirow{4}{*}{$\begin{array}{l}\text { Recognizing } \\
\text { assumptions }\end{array}$} & \multirow[t]{2}{*}{ Male } & Traditional method & 5.50 & 0.46 & 4.59 & 6.41 \\
\hline & & Reciprocal teaching & 8.37 & 0.46 & 7.46 & 9.27 \\
\hline & \multirow[t]{2}{*}{ Female } & Traditional method & 5.4 & 0.46 & 4.49 & 6.31 \\
\hline & & Reciprocal teaching & 9.23 & 0.46 & 8.33 & 10.14 \\
\hline \multirow[t]{4}{*}{ Deduction } & \multirow[t]{2}{*}{ Male } & Traditional method & 6.43 & 0.59 & 5.28 & 7.59 \\
\hline & & Reciprocal teaching & 16.87 & 0.59 & 15.71 & 18.03 \\
\hline & \multirow[t]{2}{*}{ Female } & Traditional method & 6.13 & 0.59 & 4.98 & 7.29 \\
\hline & & Reciprocal teaching & 15.17 & 0.59 & 14.01 & 16.33 \\
\hline \multirow[t]{4}{*}{ Interpretation } & \multirow[t]{2}{*}{ Male } & Traditional method & 4.43 & 0.42 & 3.59 & 5.27 \\
\hline & & Reciprocal teaching & 9.47 & 0.42 & 8.63 & 10.31 \\
\hline & \multirow[t]{2}{*}{ Female } & Traditional method & 4.07 & 0.42 & 3.23 & 4.91 \\
\hline & & Reciprocal teaching & 7.17 & 0.42 & 6.33 & 8.01 \\
\hline \multirow{4}{*}{$\begin{array}{l}\text { Evaluating } \\
\text { arguments }\end{array}$} & \multirow[t]{2}{*}{ Male } & Traditional method & 5.03 & 0.39 & 4.27 & 5.8 \\
\hline & & Reciprocal teaching & 9.13 & 0.39 & 8.37 & 9.9 \\
\hline & \multirow[t]{2}{*}{ Female } & Traditional method & 4.80 & 0.39 & 4.04 & 5.56 \\
\hline & & Reciprocal teaching & 7.10 & 0.39 & 6.34 & 7.86 \\
\hline \multirow[t]{4}{*}{ Overall } & \multirow[t]{2}{*}{ Male } & Traditional method & 28.30 & 1.42 & 25.49 & 31.11 \\
\hline & & Reciprocal teaching & 57.73 & 1.42 & 54.93 & 60.54 \\
\hline & \multirow[t]{2}{*}{ Female } & Traditional method & 27.53 & 1.42 & 24.73 & 30.34 \\
\hline & & Reciprocal teaching & 51.67 & 1.42 & 48.86 & 54.47 \\
\hline
\end{tabular}

Table 7 reveals the result $(F(1,118)=336.64$, sig $=0.001$ $(\mathrm{p}<0.05))$, indicating a statistically large variation between the control and experimental groups in the total average critical thinking test scores in favour of the experimental group. The following are the findings for the sub-skills of critical thinking: $F(1,118)=103.67$, sig $=0.001(\mathrm{p}<0.05)$ for inference, indicating a large variation between the average of an experimental group and the control group for the inference result in favour of the experimental group who were taught physics via reciprocal teaching. The value for recognising assumptions was $F(1,118)=53.5$, sig $=0.001 \quad(p<0.05)$. It indicates large variations between the average of an experimental group and the control group for recognising assumptions, with the experimental group having been taught physics via reciprocal teaching. The score of $F(1,118)=271.51$, sig $=0.001 \quad(p<0.05)$ for deduction indicates a large variation between the average of an experimental group and the control group for the deduction result in favour of the experimental group who were taught physics via reciprocal teaching. $\mathrm{F}(1,118)=82.66$, sig $=0.001 \quad(\mathrm{p}<0.05)$ for interpretation indicating a large variation between the average of an experimental group and the control group for the interpretation result in favour of the experimental group who were taught physics via reciprocal teaching. $F(1$, $118)=62.63$, sig $=0.001(p<0.05)$ for evaluating arguments, indicating a large variation between the average of the experimental group and the control group for evaluating arguments result in favour of the experimental group who were taught physics via reciprocal teaching. On the basis of previous research, the current study's findings are symmetric with previous findings (Ahiri et al., 2018; Arafa, \& Miqdadi, 2016; Lestari, 2016; Rasmuin et al., 2019; Shshaw, 2018; Sundahry et al., 2018).

\section{Difference of Critical Thinking Skills According to Group and Gender}

Critical thinking test was given once the intervention was completed. The average and criteria deviation for students' marks in the five sub-skills were calculated by using descriptive statistics. Table 8 shows male and female students' scores in the critical thinking test. 
Table 9. Test of between-subjects effects on critical thinking subskills

\begin{tabular}{|c|c|c|c|c|c|c|c|}
\hline Source & Dependent variable & $\begin{array}{l}\text { Type III sum } \\
\text { of squares }\end{array}$ & Df & $\begin{array}{l}\text { Mean } \\
\text { square }\end{array}$ & $\mathrm{F}$ & Sig & Partial $\eta^{2}$ \\
\hline \multicolumn{2}{|c|}{ Gender/Method Inference } & 6.08 & 1 & 6.08 & 0.54 & 0.46 & 0.005 \\
\hline & Recognising assumption & 7.01 & 1 & 7.01 & 1.11 & 0.29 & 0.009 \\
\hline & Deduction & 14.70 & 1 & 14.70 & 1.43 & 0.23 & 0.012 \\
\hline & Interpretation & 28.03 & 1 & 28.03 & 5.19 & 0.03 & 0.043 \\
\hline & Evaluating arguments & 24.30 & 1 & 24.30 & 5.46 & 0.02 & 0.045 \\
\hline & Overall & 210.68 & 1 & 210.68 & 3.50 & 0.064 & 0.029 \\
\hline
\end{tabular}

Table 8 shows the post-test results for students who were taught physics by using the reciprocal teaching approach. The average value for male students was 57.73, whereas the average value for female students was 51.67. However, the post-test results for students who have been taught physics by utilizing the traditional method were almost approximant values. The average score for male students was 28.3, whereas the average score for female students was 27.53. Therefore, using a reciprocal teaching method helped both male and female students enhance their critical thinking skills. The variation in average between the male and female groups favors male students who received reciprocal teaching method to learn physics. Table 7 shows a variation between the male and female groups in the first subskill of critical thinking (inference), with the male group having an average value of 14.07 and the female group having an average value of 13.47. The results show that the average value for post-test students taught physics via the traditional method was 7.4, and the average value for female students was (7.7).

Similarly, results show a divergence between the male and female in favor of female students who were taught physics via the reciprocal teaching strategy regarding the second subskill of critical thinking, recognizing assumptions. The average value for male students was 8.37, whereas that for female students was 9.23. The results of the post-test for students who have been taught physics by the traditional method, and the average value for male students was 5.5. The average for female students was 5.4. The results on deduction showed an average variation in favor of male students who were taught physics via the reciprocal teaching strategy, where the average value for male students was 16.87, whereas that for female students was 15.17. In the results of post-test for students who were taught physics via the traditional method, the average value for male and female students were 6.43 and 6.13, respectively. The results of the fourth subskill a statistical variation in favor of male students who were taught physics using the reciprocal teaching strategy, where the average value for male students was 9.47. However, the average value for female students was 7.17. In the results of the posttest for students who were taught physics using traditional methods, the average value for male students was 9.47, whereas that for female students was 4.07 . The results for evaluating argumentations revealed a statistical variation in favour of male students who were taught through the reciprocal teaching, where the average value for male students was 9.13 and that for female students was 7.1.

Furthermore, the average post-test values for students who have been taught through the traditional method was 5.03 for male students and 4.8 for female students. Testing the effect of the reciprocal teaching strategy on attractive critical thinking abilities among Palestinian 10th-grade students, the investigation of addition scores gives equitable outcomes in a lot more extensive cluster of exploration plans. This count assesses the impact between two methods (upgrades from pre-test to post-test for entire gatherings) (Cohen et al., 2007). First, a factorial two-way MANCOVA was used to determine if the research's two independent variables interact with one another. This step was done to determine if the reciprocal teaching technique and the traditional method impacted the study subjects' critical thinking skills. No important interaction effects were observed between method and gender Wilks' lambda $=0.92 \mathrm{~F}(6,111)=1.62, \operatorname{sig}=0.150 \quad(\mathrm{p}>0.05)$ with partial $\mathrm{\eta} 2=0.08$, indicating that only $8 \%$ of the total variance accounts for the interaction effects between teaching method and gender. In order to assess the amount to which the reciprocal teaching approach and the traditional method had affected critical thinking skills, study employed a between-subject comparison test for the method in the critical thinking exam to identify the variation within groups. Table 9 presents the between-subjects test of all dependent variables.

The value $F(1,116)=3.50$, sig $=0.064(p>0.05)$ in Table 9 presents no considerable variation in the average scores of the gender interaction (male and female) and method (reciprocal teaching and traditional method) on the overall result of the test. Additionally, the results for the sub-skills are: in terms of inference, the value was $F(1,116)=0.54, p=0.46 \quad(p>0.05)$, which articulates no considerable variation between the average of the interaction between gender (male and female) and method (reciprocal teaching and traditional method) for inference skill. However, the value of recognising assumptions was $F(1,116)=1.11$, sig $=0.29(p>0.05)$, which does not indicate much of a variation between the average of the gender interaction and the average of the interaction between gender (male and female) and method (reciprocal teaching and traditional method) for 


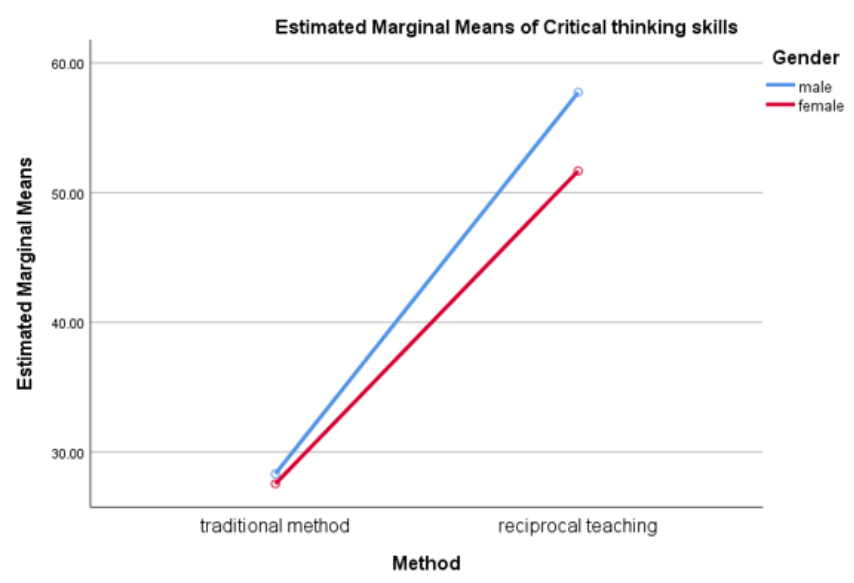

Figure 2. Comparison of the average scores of interactions between gender (male/female) and method (reciprocal teaching/traditional method) on the critical thinking test

recognising assumptions. The value of deduction was $F(1,116)=1.43$, sig $=0.23$ ( $p>0.05)$, which articulates that there is not any considerable variation between the average of the interaction between gender (male and female) and method (reciprocal teaching and traditional method) for deduction skills. However, the value for interpretation was $\mathrm{F}(1,116)=5.19, \mathrm{p}=.03 .05)$. The average gender interaction (male and female) and technique (reciprocal teaching and conventional method) for interpretation is statistically considerable. Similarly, when it comes to evaluating argument skill, there is a considerable variation in the average of the gender interaction (male and female) and technique (reciprocal teaching and conventional method), with the value $\mathrm{F}(1$, 116) $=5.46, \mathrm{p}=.02 .05$.

Overall, the results of this study show a considerable variation in critical thinking skills and subskills between the experimental and control groups, as well as between pre-and post-tests, favouring the experimental group. However, for the interaction between gender (male and female) and method (traditional method and reciprocal teaching strategy), the findings reveal a considerable variation in interpretation and evaluation abilities between the experimental and control groups favouring male students. However, there is no considerable variation between male and female critical thinking abilities regarding inference, recognising assumptions and deduction skills. Generally, there was a variation between (male and female) and (reciprocal teaching and traditional method) in critical thinking skills favouring male students who learn physics through reciprocal teaching strategy as shown in Figure 2.

However, in the subskill of interpretation, there was the variation between (male and female) and (reciprocal teaching and traditional method) favouring male students whose learn physics through reciprocal teaching strategy as shown in Figure 3.

In addition, in evaluating arguments, there was the variation between (male and female) and (reciprocal

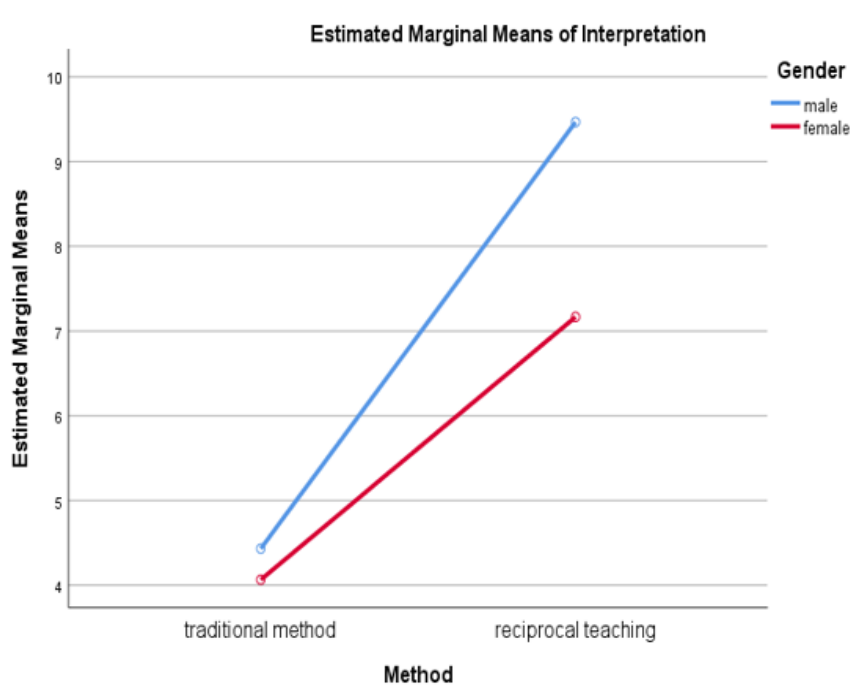

Figure 3. Comparison of the average scores of interactions between gender (male/female) and method (reciprocal teaching/traditional method) on the interpretation subskill

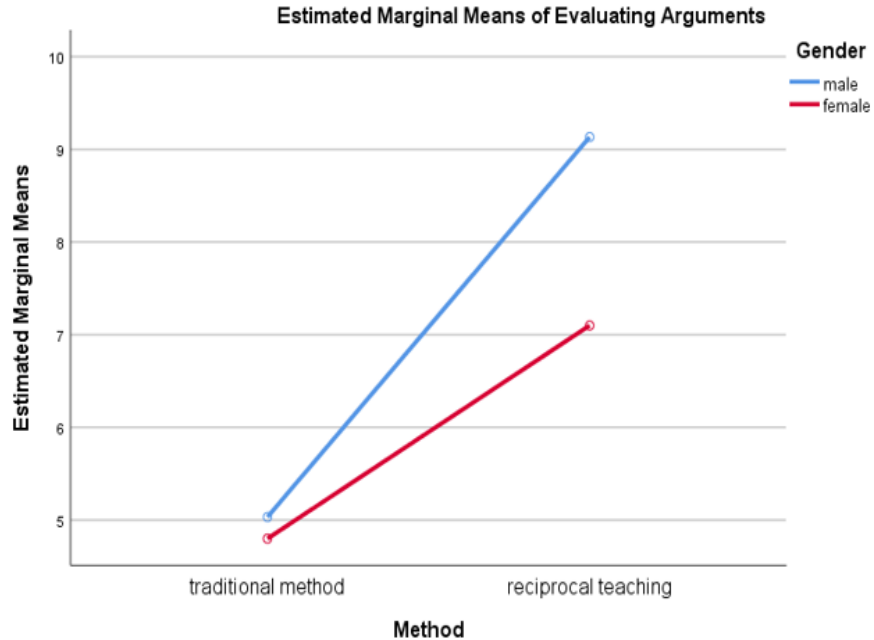

Figure 4. Comparison of the average scores of interaction between gender (male/female) and method (reciprocal teaching/traditional method) on the evaluating arguments subskill

teaching and traditional method) favouring male students whose learn physics through reciprocal teaching strategy as shown in Figure 4.

\section{DISCUSSION}

The findings of this study's critical thinking test revealed that using a reciprocal teaching strategy (experimental group) for teaching physics is more effective than using a traditional method (control group) in improving overall critical thinking and the sub-skills of inference, recognising assumptions, deduction, interpretation and evaluating arguments among the selected 10th-grade students (Alemu, 2020; Olimat et al., 2018; Sundahry et al., 2018). The reciprocal teaching strategy urged students in the experimental group 
learning environment to think and appears to have the power to develop students' ability to make judgments, test hypotheses, present arguments, summarise text, give feedback, make a connection between information and interpretations independent from the textbook and teacher's control (Meyer, 2014). The physics teacher must understand that helping learners acquire critical thinking skills does not come through lectures and explanation of the text, but in guiding learners to study and discover experiments and interact among themselves and the teacher (Meyer, 2014). This can be achieved by providing students with problem-solving physics tasks to challenge their thinking, getting them to a state of alertness and attention. According to the quantitative findings, the reciprocal teaching method helps students improve their critical thinking abilities while learning physics (Jawad, 2020; Sulasih et al., 2018). Finally, there is no statistically significant difference in the mean scores of critical thinking skills between the experimental group students who were taught physics via reciprocal teaching and control group students who were taught physics via the traditional method; hence, the first hypothesis was rejected.

The findings of the current study are consistent with other studies that argue the variation between reciprocal teaching and the traditional method in favour of reciprocal teaching to improve critical thinking skills better than the traditional method for secondary school students in science subjects (Ahiri et al., 2018; AL Shshaw, 2018; Arafa \& Miqdadi, 2016; Lestari, 2016; Sundahry et al., 2018). In addition, there is an improvement in academic performance when reciprocal teaching is used to improve critical thinking skills. Students can link theory that they learned virtually and use that to upgrade their general shows awareness. They are able to understand and critique, which helps in deeper understanding that will be evident in the grades. Critical thinking also helps students in understanding the views and perspectives of others as well and enhancing the ability to work in teams. For example, the team activities that has to be done with school students needs listening to the peers for completing the given task, rather than just going with a single thought of an individual. This makes a student learn that there can be numerous solutions to a single problem and allows them to work together while agreeing on one. Such activities that require Critical thinking helps in the development of a student to cooperate and not take decisions on assumptions' (AL-Miqdadi, 2017; Ameer, 2017; Arafa \& Miqdadi, 2016; Capanzana \& Avilla, 2017; Mulyono et al., 2018; Sundahry et al., 2018).

Elsie (2014) found a concordable distinction among the positive aspects of all the different school groups and the experimental group. For the critical thinking subskills, firstly, inference skills differ between groups favouring the experimental group. Secondly, recognising assumption skill is entirely different between groups favouring the experimental group who learns physics (mechanics) through reciprocal teaching. Thirdly, deduction skills are significantly different between groups concerning the experimental group who learn physics through reciprocal teaching. Fourthly, the experimental group's interpretation skills are far superior than the control group's. Finally, the experimental group outperforms the control group when it comes to assessing argument skills. However, the results of the interaction between gender (male and female) and teaching method (traditional method and reciprocal teaching strategy) revealed a significant difference between the control and experimental groups in interpretation and evaluating arguments skills in favour of male students who learn physics via reciprocal teaching, but no significant difference in inference, recognising assumptions and deduction. Finally, there is no statistically significant difference between the critical thinking skills of students in the 10th grade in physics due to the interaction between the method of teaching and gender was accepted for inference, recognising assumptions, and deduction critical thinking subskills and rejected for interpretation and Evaluating arguments critical thinking subskills.

Several past studies thought that the reciprocal teaching method was a good fit for teaching physics because it would be difficult to control the classroom and time (Agoro \& Akinsola, 2013; Alemu, 2020; Ameer, 2017; Capanzana \& Avilla, 2017; Zaman, 2019). Therefore, the researcher of the presented study suggests conducting the following studies in the future, such as the effect of reciprocal teaching in the development of other higher-order thinking skills (scientific, reflective and creative thinking) among students of various educational levels and subjects. Furthermore, the researcher compared the reciprocal teaching strategy and other educational methods or techniques for different higher-order thinking skills (critical, creative, scientific and reflective thinking and other variables). Moreover, the researcher conducted a similar study of the current research to discover the effect of reciprocal teaching strategy at different levels, such as primary schools, teacher institutes and tertiary-level teachers (faculty of education), not only for physics but also for various subjects in science taking into consideration other variables such as cultural background.

Reciprocal teaching was found better than traditional methods for grade 10 physics. Therefore, physics teachers are recommended to use reciprocal teaching strategy for the improvement of students critical thinking ability. Teachers are recommended to be trained for better implementation of reciprocal teaching in classrooms, and training should be provided to class teachers using the eight steps of reciprocal teaching. The present system of education in Palestine is highly emphasised on cognitive development of students; hence, RT strategy is highly recommended for students 
of physics to enhance their cognitive and metacognitive at secondary level. The results of the study are recommended to be shared with stakeholders concerned with curriculum development and policymaking at secondary level in order to make better decisions for the incorporation of reciprocal teaching, related materials and training.

\section{CONCLUSIONS}

Reciprocal teaching has improved critical thinking skills for both male and female students, with high successes in the experimental group. As used in physics for 10th-grade students, the reciprocal teaching strategy proved superior to the traditional method. The technique has a high impact on the growth of the intelligence portion of students' cognitive and metacognitive domains at the secondary level. The RT method has strongly developed the implementation aspect of cognitive, metacognitive and critical thinking skills in physics for experimental group learners in physics critical thinking skills (mechanics). There are numerous implications for stakeholders (e.g., scholars, policymakers, teachers, and students) on the basis of data given in this study to encourage the implementation of an integrated reciprocal teaching strategy in schools.

Author contributions: All authors have sufficiently contributed to the study, and agreed with the results and conclusions.

Funding: No funding source is reported for this study.

Acknowledgements: The authors express their gratitude to the Ministry of Higher Education in Palestine for their assistance in data collecting and the students and professors who participated.

Declaration of interest: No conflict of interest is declared by authors.

\section{REFERENCES}

Agnes, M. (2013). Webster new world collegiate dictionary. Pocket Books.

Agoro, A. A., \& Akinsola, M. K. (2013). Effectiveness of reflective-reciprocal teaching on pre-service teachers' achievement and science process skills in integrated science. International Journal of Education and Research, 1(8), 1-20.

Ahiri, Y., Yuniarsih, T., \& Rasto. (2018). The effect of reciprocal teaching and group investigation toward students' critical thinking skills. International Journal of Education, Learning and Development, 6(3), 37-46.

AL Shshaw, Z. (2018). Reciprocal teaching strategy the achievement, thinking metacognition skill. Faculty of Education for Human Sciences $\backslash$ University of ALBasra, 38, 877- 901.

Alemu, M. (2020). Improving secondary school students' physics achievement using reciprocal peer tutoring: A multi-level quasi-experimental study. EURASIA Journal of Mathematics, Science and
Technology Education, 16(4), 1-14. https://doi.org/ 10.29333 / ejmste/115164

Aljaafreh, I. (2013). The effect of using the directed inquiry strategy on the development of critical thinking skills and achievement in physics of the tenth grade students in southern Mazar. Journal of Education and Practice, 4(27), 191-198.

AL-Miqdadi, L. (2017). The effect of an instructional program based on reciprocal teaching in solving mathematical problems and critical thinking skills among students in elementary schools according to their achievement levels. Journal in Educational Sciences, Jordan, 13(2), 193-208.

Alsaraireh, M. Y. A., \& Hamid, K. M. N.K. (2016). The effect of the reciprocal teaching model on developing Jordanian students' reading comprehension at Mutah University. International Journal of Linguistics, 1(8), 69-93. https://doi.org/ 10.5296/ijl.v8i6.10448

Ameer, S. M. A. (2017). The effect of using teaching exchange strategy in acquiring biology for the second intermediate female students. Basic Education College Magazine for Educational and Humanities Sciences, 33, 432-449.

Arafa, L., \& Miqdadi, A. (2016). The effect of an instructional program based on reciprocal teaching in solving mathematical problems and critical thinking skills among students in elementary schools according to their achievement levels. Jordanian Journal in Educational Science, 13(2), 193208.

Araujo, S. P., \& Carneiro, M. H. S. (2016). Reading in biology classes-A different teaching activity. Journal of Scientific Research, 7(7), 1044-1050. https:/ / doi.org/10.4236/ce.2016.77108

Blazer, C. (2007). Reciprocal teaching. https:/ / files.eric.ed.gov/fulltext/ED541081.pdf

Brown, A. L. (1987). Metacognition, executive control, self-regulation, and other more mysterious mechanisms. In F. E. Weinert, \& R. H. Kluwe (Eds.), Metacognition, motivation, and understanding (pp. 65116). Erlbaum.

Capanzana, C. O., \& Avilla, R. A. (2017). Reciprocal teaching approach with self-regulated learning (RT-SRL): Effects on students' reading comprehension, achievement and self-regulation in chemistry. The Normal Lights,11 (2), 31-59.

Cohen, L., Manion, L., \& Morrison, K. (2007). Research methods in education. The Taylor \& Francis eLibrary. https:/ / doi.org/10.4324/9780203029053

Elsie, F. (2014). Reciprocal teaching: Investigation of its effectiveness as a method of whole-class reading comprehension instruction at key stage two [Unpublished dissertation]. The University of London. 
Ennis, R. (2011). Critical thinking: Reflection and perspective part I. Inquiry: Critical Thinking Across the Disciplines, 26(1), 4-18. https://doi.org/ 10.5840 /inquiryctnews20112613

Flavell, J. H. (1976). Metacognitive aspects of problemsolving. In L. B. Resnick (Ed.), The nature of intelligence (pp. 231-235). Erlbaum.

Galloway, S. (2009). Theory-based evaluation and the social impact of the arts. Cultural Trends, 18(2), 125148. https:/ / doi.org/10.1080/09548960902826143

George, D., \& Mallery, M. (2010). SPSS for windows step by step: A simple guide and reference. Pearson.

George, D., \& Mallery, P. (2016). IBM SPSS statistics 23 step by step: A simple guide and reference. Routledge.

Guise, M., Habib, M., Thiessen, K., \& Robbins, A. (2017). Continuum of co-teaching implementation: Moving from traditional student teaching to coteaching. Teaching and Teacher Education, 66, 370382. https://doi.org/10.1016/j.tate.2017.05.002

Hyun, J., Ediger, R., \& Lee, D. (2017). Students' satisfaction on their learning process in active learning and traditional classrooms. International Journal of Teaching and Learning in Higher Education, 29(1), 108-118.

Jawad, M. M. (2020). The effectiveness of cross-teaching strategy in achieving and developing scientific thinking among middle school students in physics. Journal of Babylon Center for Humanities Studies, 10(2), 135-172.

Koch, A., \& Eckstein, G. (2005). Skills needed for reading comprehension of physics texts and their relation to problem-solving ability. Journal of Research in Science Teaching, 32(6), 613-628. https://doi.org/ 10.1002 / tea.3660320607

Larsson, K. (2017). Understanding and teaching critical thinking - A new approach. International Journal of Educational Research, 84, 32-42. https://doi.org/ 10.1016/j.ijer.2017.05.004

Maciejewski, M. L. (2018). Quasi-experimental design. Biostatistics E Epidemiology, 1-10. https://doi.org/ 10.1080/24709360.2018.1477468

Meyer, K. (2014). Making meaning in mathematics problem-solving using the reciprocal teaching approach. Literacy Learning: The Middle Years, 22(2), 7-14.

Ministry of Education MOE. (2019). Education statistics yearbook, 2019/2020.

Monica, K. M. M. (2005). Development and validation of a test of integrated science process skills for further education and training learners. [Master thesis, University of Pretoria South Africa]. http:/ / upetd. up.ac.za/thesis/available/etd-04302008-145702/

Navaie, L. A. (2018). The effects of reciprocal teaching on reading comprehension of Iranian EFL learners.
Advances in Language and Literary Studies, 9, 26-30. https:/ / doi.org/10.7575/aiac.alls.v.9n.4p.26

Noone, C., \& Hogan, M. J. (2016). A protocol for a randomised active-controlled trial to evaluate the effects of an online mindfulness intervention on executive control, critical thinking and critical thinking dispositions in a university student sample. BMC Psychology, 1-12. http://doi.org/ 10.1186/s40359-016-0122-7

Oczkus, L. (2003). Introduction. Reciprocal teaching at work: strategies for improving reading comprehension. International Reading Association.

Oczkus, L. (2013). Reciprocal teaching, powerful handson comprehension strategy. The Utah Journal of Literacy, 16(1), 34-38.

Olimat, A. Omari, W., \& Alshannaq, M. (2018). The effectiveness of reciprocal teaching strategy in improving critical thinking skills in mathematics among students of a class teacher at The Hashemite University. AL-Manara Journal, 24(4), 498-528.

Oludipe, O. (2014), Thoughts on reciprocal teaching in chemistry. https://septiriyan.wordpress.com/2012 /09/30/reciprocal-teaching-applied-to-unders tand-chemistry-concepts/\#comments

Palincsar, A. S., \& Brown, A. L. (1984). Reciprocal teaching of comprehension fostering and comprehension monitoring activities. Cognition and Instruction, 1(2), 117-175. https:/ / doi.org/10.1207/ s1532690xci0102_1

Phillipa, J. Q. (2010). Using reciprocal teaching [Master thesis, Massey University]. https://muir.massey. ac.nz/bitstream/handle/10179/2247/02_whole.p $\mathrm{df}$

Piaw, C. Y. (2010). Building a test to assess creative and critical thinking simultaneously. Procedia- Social and Behavioural Sciences, 2(2), 551-559. https:/ / doi.org/ 10.1016/j.sbspro.2010.03.062

Pituch, K. A., \& Stevens, J. P. (2016). Applied multivariate statistics for the social sciences: Analyses with SAS and IBM's SPSS. Routledge. https://doi.org/10.4324/ 9781315814919

Pressley, M., Forrest-Pessley, D. L. Elliott-Faust, D., \& Millert, G. (1985). Children's use of cognitive strategies, how to teach strategies, and what to do if they can't be taught. In M. Pressley, \& C. J. Brainerd (Eds.), Cognitive learning and memory in children (pp. 1-47). Springer-Verlag. https: / / doi.org /10.1007/978-1-4613-9544-7_1

Rabari, J., Indoshi, F., \& Okwach, T. (2011). Correlates of divergent thinking among secondary school physics students. Educational Research, 2(3), 982-996.

Renjith K, R., \& James, R. (2015). Evaluation of critical thinking in higher education in Oman. International Journal of Higher Education, 4(3), 33-43. https:/ / doi.org/10.5430/ijhe.v4n3p33 
Song, X. (2016). "Critical thinking" and pedagogical implications for higher education. East Asia, 33(1), 25-40. https:// doi.org/10.1007/s12140 015-9250-6

Star, J. R. (2013). For struggling learners, how do we fill their gaps and teach them on grade level all in one year. http://researchmap.digitalpromise.org/ask_a_res earcher/struggling-learners-fill-gaps-teach-gradelevel-one-year

Stephanou, G., \& Mpiontini, M. (2017). Metacognitive knowledge and metacognitive regulation in selfregulatory learning style, and its effects on performance expectation and subsequent performance across diverse school subjects. Psychology, 8, 1941-1975. https:/ / doi.org/10.4236/ psych.2017.812125

Sulasih, Sarwanto, \& Suparmi. (2018). Physics learning with metacognitive approach through problem based learning (PBL) and reciprocal learning (RL) model viewed from students' critical thinking Skill. International Journal of Pedagogy and Teacher Education, 2, 69-78. https://doi.org/10.20961/ ijpte.v2i0.19896

Sundahry, S., Fitria Y., \& Rakimahwati, R. (2018). The effect reciprocal teaching strategy of critical thinking skills in learning thematic class V. International Conferences on Education, Social Sciences and Technology, 816-822. https://doi.org/10.29210/ 20181118

Tiruneh, D. T., De Cok, M., Weldeslassie, A. G., Elen, J., \& Janssen, R. (2017). Measuring critical thinking in physics: Development and validation of a critical thinking test in electricity and magnetism. International Journal of Science and Mathematics Education, 15(4), 663-682. https:// doi.org/10.1007/ s10763-016-9723-0

Tiruneh, D. T., Gu, X., De Cock, M., \& Elen, J. (2018). Systematic design of domain-specific instruction on near and far transfer of critical thinking skills. International Journal of Educational Research, 87, 1-11. https:/ / doi.org/10.1016/j.ijer.2017.10.005

Vygotsky, L. S. (1978). Mind in society: The development of higher psychological processes. Harvard University Press.

Watson, G., \& Glaser, E. M. (1980). Watson-Glaser critical thinking manual. The Psychological Corporation, Hartcourt Brace.

Watson, G., \& Glaser, E. M. (2008). Watson-Glaser critical thinking appraisal: Forms $A$ and $B$ manual. Pearson Education.

Watson, G., \& Glaser, E. M. (2010). Watson-Glaser II critical thinking appraisal. NCS Pearson.

Yildirim, B., \& Ozkerman, S. (2011). Critical thinking in nursing and education. International Journal of Humanities and Social Science, 1(13), 257-262.

Yvonne, R., Jodie, P., \& Elizabeth, B. (2009). Reciprocal teaching in mathematics. https://ww.mav.vic.edu. au/files/conferences/2009/13Reilly.pdf

Zaman, A. (2019). Effects of reciprocal teaching on students' achievement in physics at secondary level. Journal of Science Education, 1(2), 31-44.

\section{https://www.ejmste.com}

